\title{
IDENTIFIKASI MATERIAL BAWAH PERMUKAAN KECAMATAN BONTOCANI KABUPATEN BONE MENGGUNAKAN METODE GEOMAGNET
}

\author{
Nur Inayah Duhri*), Vistarani Arini Tiwow, dan Nasrul Ihsan \\ Jurusan Fisika, FMIPA Universitas Negeri Makassar \\ Jl. Daeng Tata Raya Kampus UNM Parangtambung, Makassar 90224 \\ ${ }^{*}$ Email: nurinayahd6@gmail.com
}

\begin{abstract}
Abstrak. Penelitian tentang identifikasi material bawah permukaan Kecamatan Bontocani Kabupaten Bone dengan metode geomagnet telah dilakukan. Penelitian ini bertujuan untuk menganalisis sebaran material bawah permukaan Kecamatan Bontocani Kabupaten Bone. Lokasi penelitian berada pada koordinat $05^{\circ} 9^{\prime}-04^{\circ} 54^{\prime}$ LS dan $11^{\circ} 54^{\prime}-120^{\circ} 6^{\prime}$ BT. Proses akuisisi data dilakukan pada enam lintasan dengan satu base station menggunakan alat Proton Procession Magnetometer (PPM) Geotron G5. Selanjutnya, dilakukan koreksi harian dan koreksi IGRF 42918,2 nT dan diperoleh nilai kemagnetan pada rentang -700 nT-1600 nT. Dan selanjutnya dimodelkan dengan aplikasi Surfer 10 hingga tampak variasi anomali kemagnetan terendah -700 nT-100 nT hingga tertinggi $1100 \mathrm{nT}-1600 \mathrm{nT}$. Upward continuitas sebesar $100 \mathrm{~m}$ menggunakan software Magpick menghasilkan nilai kemagnetan regional sebesar -3000 nT-4000 nT. Data hasil upward dibentuk sayatan sebanyak 2 sayatan pada bidang anomali magnetik dan dimodelkan menggunakan software Mac2DC. Hasil pemodelan menunjukkan material bawah permukaan yaitu pirit (0.05-5 nT), basalt (0.2-175 nT), dan Av batuan sedimen (0-18 nT). Mineral pirit tersebar di daerah penelitian yang berasosiasi dengan breksi.
\end{abstract}

Kata Kunci: material bawah permukaan, metode geomagnet, mineral pirit

\begin{abstract}
The study of the identification of subsurface material in the Bontocani District of Bone Regency with the geomagnetic method was carried out. This study aims to analyze the distribution of subsurface material in the Bontocani District of Bone Regency. The research location is at coordinates $05^{\circ} 9^{\prime}-04^{\circ} 54^{\prime} \mathrm{LS}$ and $119^{\circ} 54^{\prime}-120^{\circ} 6^{\prime} \mathrm{BT}$. The data acquisition process is carried out on six paths with one base station using the Geotron G5 Proton Procession Magnetometer (PPM). Furthermore, daily correction and IGRF correction were performed and magnetic values were obtained in the range of -700 nT-1600 nT. Variations in magnetic field anomalies were mapped using Surfer 10 software, so that the magnetic anomaly value of -700-1600 nT was obtained. Upward continuity of $100 \mathrm{~m}$ is done using the Magpick software and produces a regional magnetic value of 3000-4000 nT. Upward data results were formed in 2 incisions in the magnetic anomaly field and modeled using Mac2DC software. The modeling results show subsurface material namely pyrite (0.05-5 nT), basalt (0.2-175 nT), and Av sedimentary rocks (0-18 nT). Pyrite minerals are scattered in the research area associated with breccias.
\end{abstract}

Keywords : subsurface material, geomagnetic method, pyrite mineral

\section{PENDAHULUAN}

Sumber daya mineral atau bahan galian adalah sumber daya yang telah terbentuk pada kulit bumi (kerak bumi/crust) melalui berbagai macam proses yang dilewatinya. Adapun bahan galian sifatnya tidak dapat diperbaharui, jumlahnya yang terbatas serta proses pembentukan yang memerlukan waktu ribuan tahun bahkanjutaan tahun. Setiap bahan galian memiliki kandungan mineral yang berbeda berdasarkan proses pembentukannya. Mineral dapat didefinisikan sebagai bahan padat anorganik yang terbentuk secara alamiah dan terdiri unsur-unsur kimiawi dalam perbandingan tertentu, dimana atom-atom didalamnya tersusun mengikuti suatu pola yang sistematis.

Kabupaten Bone merupakan salah satu kabupaten di provinsi sulawesi selatan yang memiliki potensi mineral yang tersebar di Kecamatan Bontocani seperti endapan biji besi yaitu magnetit $\left(\mathrm{Fe}_{3} \mathrm{O}_{4}\right)$ berwarna abu-abu dengan kilap logam, kemagnetan kuat-sangat kuat dengan hematit $\left(\mathrm{Fe}_{2} \mathrm{O}_{3}\right)$ berwarna abu-abu terang hingga kemerahan, dengan kemagnetan lemahsedang (Harry Utoyo, 2008). 
Daerah lokasi penelitian di Kecamatan Bontocani Kabupaten Bone memiliki kandungan bahan tambang yang cukup melimpah, terbukti karena adanya tambang bijih besi yang sudah beroperasi beberapa tahun lalu yakni di Dusun Tanjung Kelurahan Kahu. Tambang yang berlokasi di dusun Tanjung kelurahan kahu kemudian berhenti beroperasi karena permasalahan perizinan (Hidayah, 2017).

Metode geomagnet merupakan metode pengolahan data potensi untuk memperoleh gambaran bawah permukaaan bumi yang berdasarkan karakteristik magnetiknya. Metode geomagnet memanfaatkan sifat kemagnetan bumi sehingga didapat kontur yang menggambarkan distribusi suseptibilitas batuan di bawah permukaan pada arah horizontal. Dari nilai suseptibilitas batuan maka dapat memisahkan batuan yang mengandung sifat kemagnetan dengan yang tidak mengandung sifat kemagnetan, sehingga dapat menentukan arah sebaran batuan itu sendiri. Untuk pemodelan kearah horizontal maka didapat informasi kedalamannya, sehingga metode ini dapat digunakan untuk mengetahui arah sebaran dan kedalaman batuan yang mengandung sifat kemagnetan maupun yang tidak mengandung sifat kemagnetan (Rusita, dkk 2016).

Metode geomagnetik dapat digunakan untuk menentukan struktur geologi bawah permukaan seperti patahan, lipatan, intrusi batuan beku, dan reservoir panas bumi (Santosa, 2013). Metode magnetik bekerja berdasarkan pengukuran variasi kecil intensitas medan magnet di permukaan bumi yang disebabkan karena perbedaan sifat magnetisasi batuan di kerak bumi (Rusli, 2009). Perbedaan sifat kemagnetan meningkatkan keberadaan medan magnet bumi yang tidak homogen atau disebut anomali magnetik.

Beberapa penelitian yang telah dilakukan oleh Zulfitrah M., dkk (2018). Tentang identifikasi sebaran mineral sulfida (pirit) menggunakan metode geomagnet di daerah
Libureng Kabupaten Bone hasil yang diperoleh batu lempung, breksi, adesit, batu gamping, dolomite, batu gamping pasir, dan mineral pirit. Selajutnya penelitian tentang identifikasi struktur lapisan bawah permukaan daerah manifestasi emas dengan menggunakan metode magnetik di Papandaya Garut Jawa Barat. Identifikasi struktur lapisan bawah permukaan daerah manifestasi emas, kontinuasi yang dipilih adalah pada ketinggian 150 meter bahwa kontur yang rapat atau kontur yang mempunyai frekuensi tinggi sudah hilang, guna mengeliminasi efek lokal dengan kontinuasi keatas dapat terlihat dengan anomali yang muncul lebih jelas (Kahfi, dkk., 2008).

Berdasarkan hasil uraian di atas, maka sehingga penulis tertarik melakukan penelitian mengenai material bawah permukaan di Kecamatan Bontocani Kabupaten Bone. Adapun tujuan penelitian ini adalah untuk mengetahui sebaran anomali medan magnet dan material bawah permukaan di Kecamatan Bontocani Kabupaten Bone.

\section{METODE}

Lokasi penelitian ini yaitu Kecamatan Bontocani yang terletak pada koordinat $05^{\circ} 9^{\prime}-$ 04 $54^{\prime}$ LS dan $119^{\circ} 54^{\prime}-120^{\circ} 6^{\prime}$ BT Kabupaten Bone (gambar 1).

Pengukuran intensitas medan magnet total dilakukan dengan peralatan Proton Precession Magnetometer (PPM) dilengkapi dengan sensor. Instrument ini mengukur besar (magnitude) medan magnet total. PPM yang diarahkan pada titik-titk medan magnet akan beroperasi secara otomatis merekam data medan magnet. Menentukan tempat atau lokasi untuk menjadi base station harus dicari suatu tempat yang mempunyai harga pembacaan stabil. Titik base station harus jauh dari benda-benda yang mengandung sifat magnet, seperti rumah beratap seng, pagar besi, aksesoris dari logam, kendaraan, dan jaringan listrik. 
Sebelum melakukan pengukuran tentukan terlebih dahulu arah utara medan magnet bumi dengan kompas geologi, pengukuran PPM harus mengarah utara-selatan. Kemudian mencatat lokasi titik pengukuran tersebut dengan GPS. Data yang dicatat GPS selama proses pengukuran ialah lintang,bujur,dan ketinggian. Data yang diperoleh dari lapangan belum berupa data yang menunjukkan nilai anomali magnetik melainkan masih berupa data mentah hasil pengukuran yang dilakukan dimana masih terdapat pengaruh dari dalam dan luar bumi. Oleh karena itu dibutuhkan koreksi terhadap data lapangan dengan tujuan untuk mendapatkan nilai anomali magnetik yang sudah dipengaruhi oleh nilai magnetik dari dalam dan luar bumi.

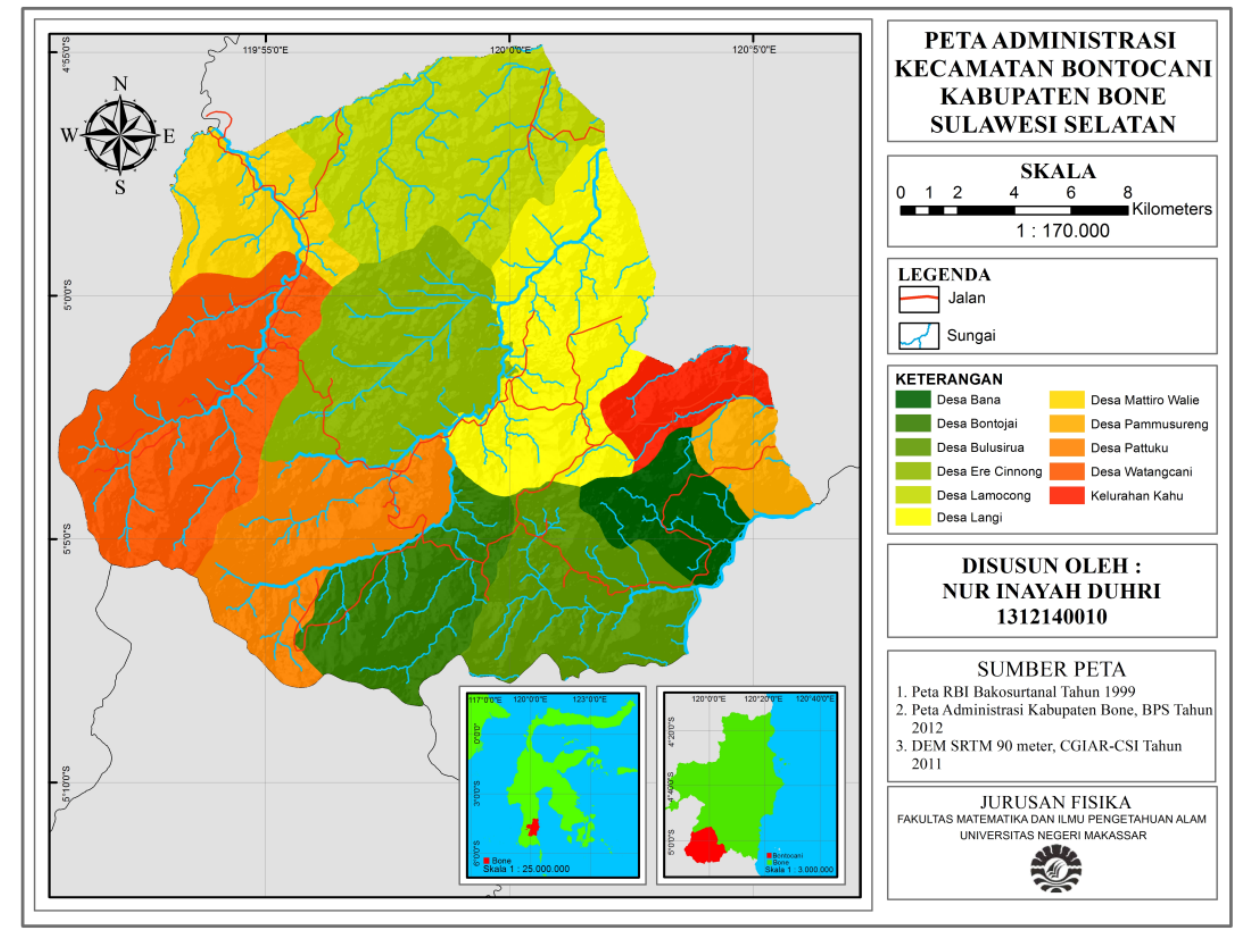

Gambar 1. Peta Kecamatan Bontocani Kabupaten Bone

Terdapat dua koreksi utama yang diterapkan pada data lapangan yaitu koreksi IGRF dan Koreksi harian. Koreksi IGRF digunakan untuk menghilangkan pengaruh medan magnet dari dalam bumi yang disebanbkan oleh medan magnet utama serta medan magnet dari kerak bumi. Sedangkan koreksi harian berfungsi untuk menghilangkan pengaruh medan magnetik yang berasal dari luar bumi. Selain itu dilakukan koreksi drift yang berfungsi sebagai faktor koreksi data base. Tujuan dilakukan koreksi ini untuk melihat perubahan nilai intensitas magnetik di base station yang bergantung pada waktu.

$$
T_{d c}=T_{o b s}-\frac{T_{b a s e 2}-T_{b a s e 1}}{t_{\text {base } 2}-t_{\text {base } 1}} \times\left(t_{\text {obs }}-t_{\text {basel }}\right)
$$

dimana:

T_dc = Nilai koreksi drift terhadap base

T_obs = Nilai magnet terukur dilapangan

$\mathrm{T}$ _base $2=$ Nilai medan magnet akhir terukur tiap station

T_base1= Nilai medan magnet awal terukur tiap station

t_base2 $=$ Waktu pengukuran akhir tiap station

t_Base1= Waktu pengukuran awal tiap station

t_obs = Waktu pengukuran medan magnet di base station 
Setelah melalui proses koreksi IGRF dan koreksi harian, maka akan didapatkan nilai anomali magnetik total lapangan yang merupakan nilai magnetik kerak bumi.

$$
\Delta T=\left(T_{o b s}-T_{I G R F}-T_{V H}\right) \pm T_{d c}
$$

dimana :

$\Delta T=$ Anomali Magnetik Total

$T_{o b s}=$ Nilai medan magnet terukur dilapangan

$T_{I G R F}=$ Nilai medan magnet utama menurut isodinamik

$T_{V H}=$ Nilai variasi harian (diurnal varition)

$T_{d c}=$ Nilai koreksi drift terhadap base

Setelah proses akhir selesai dilakukan, maka hasil akhir adalah memcari nilai anomali magnetik yang kemudian akan di plot untuk melihat hasil dari anomali magnetik tersebut. Plot dilakukan dengan menggunakan software Surfer. Kemudian melakukan grinding dimana data di input merupakan koordinat titik (X dan Y) serta data anomali magnetik. Penentuan jenis batuan dan mineral dihubungkan dengan keadaan geologi pada lokasi penelitian. Dalam penentuan nilai suseptibilitas awal, digunakan daftar suseptibilitas batuan dan mineral Telford (1998).

Pemodelan struktur bawah permukaan area penelitian menggunakan software Mag2dc. Parameter yang didapatkan nilai suseptibilitas mineral berdasarkan nilai anomali magnetik mineral bawah permukaan di Desa Kahu Kecamatan Bontocani Kabupaten Bone.

\section{HASIL DAN DISKUSI}

Metode geofisika yang dipakai untuk analisis struktur geologi bawah permukaan daerah penelitian Tanjung Kahu Kecamatan Bontocani Kabupaten Bone adalah metode geomagnetik. Pengambilan data dilakukan pada 6 lintasan. Pada daerah penelitian seluas $0.0166 \mathrm{~km}^{2}$. Pengukuran dilakukan bergantung pada target dan kondisi lapangan. Penggunaan metode magnetik ini menghasilkan kontur yang menggambarkan distribusi suseptibilitas material bawah permukaan, sehingga dari metode tersebut peneliti dapat memetakan daerah berdasarkan efek magnetik material yg ada di bawah permukaan. Data geofisika yang di dapat kemudian dihubungkan dengan data geologi untuk interpretasi lebih lanjut, karena data geofisika hanya memberikan informasi berdasarkan parameter secara fisis yang tergantung dari metode magnetik yang digunakan.

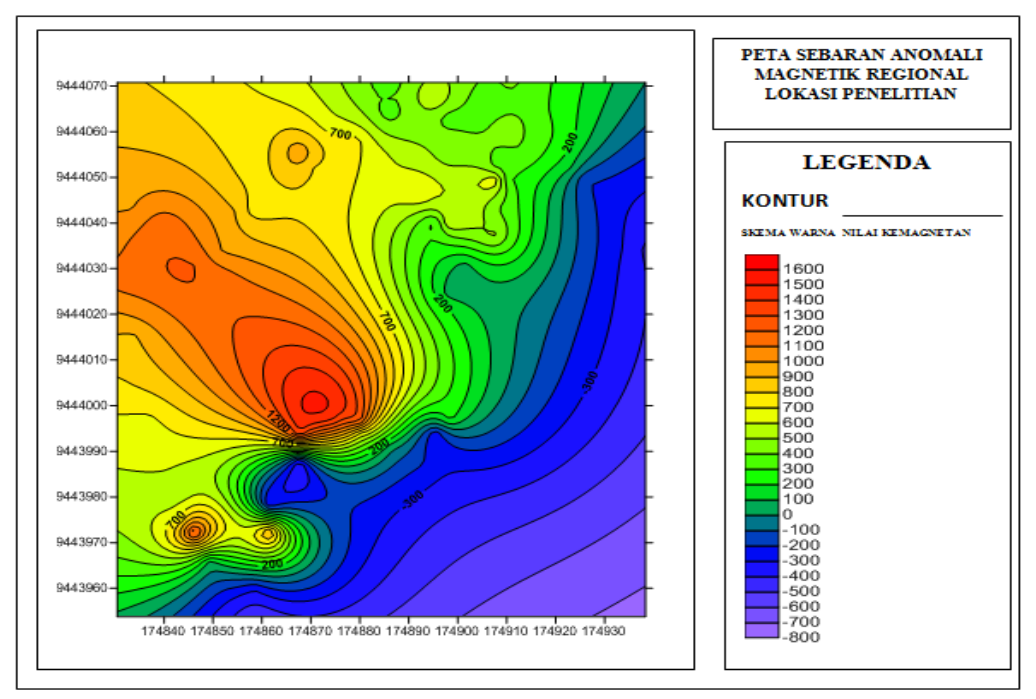

Gambar 2. Peta Kontur Anomali Mgnetik Total 
Pengambilan data dilakukan dengan menggunakan satu set alat Proton Magnetometer tipe Geotron G5 dan Global Position System (GPS) sebagai alat penunjang utama dalam proses pengambilan data. Ketika proses pengambilan data pada daerah penelitian telah dilakukan, selanjutnya dilakukan proses pengolahan data untuk kemudian diinterpretasi. Data anomali magnetik yang diperoleh sebagai nilai kemagnetan observasi mula-mula diinput kedalam program Microsoft Excel. Data hasil anomali magnetik hasil observasi di koreksi harian, koreksi IGRF, dan Koreksi Drift untuk menemukan nilai dari anomali regional. Data inilah yang dijadikan dasar untuk pengolahan data peta sebaran anomali magnet di aplikasi Surfer 10, selanjutnya peta anomali di kontinuasi ke atas dan setelah itu interpretasi.

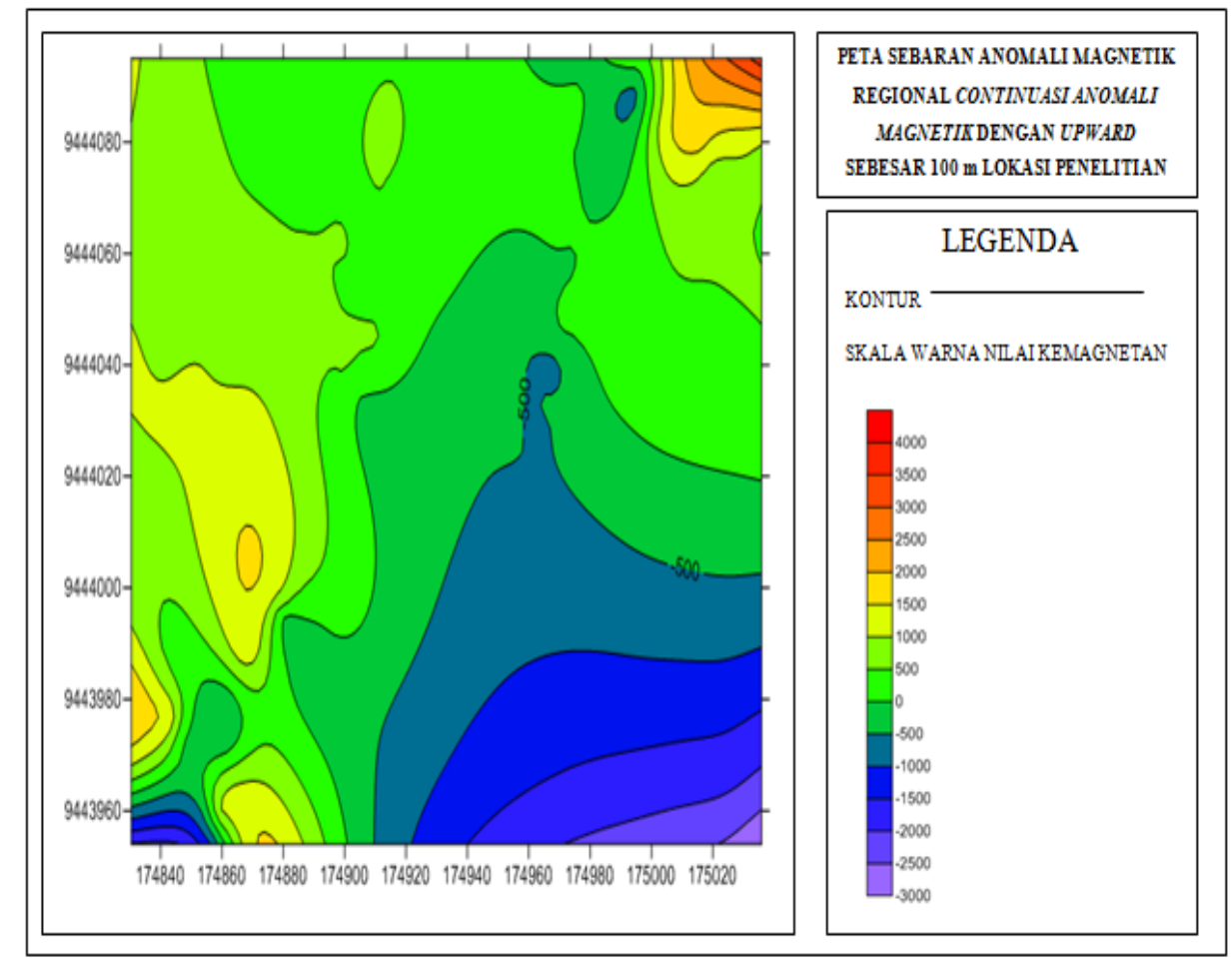

Gambar 3. Peta Kontur Continuasi Anomali Magnetik dengan Upward Sebesar 100 meter

Anomali medan magnet total diperoleh dengan melakukan beberapa koreksi pada data hasil pengukuran di lapangan, yaitu koreksi IGRF dan koreksi variasi harian. Pada peta anomali medan magnet total (gambar 2) terdapat klosur positif dan klosur negatif, hal ini menunjukkan bahwa anomali magnet adalah bersifat dipole (dwi kutub). Anomali medan magnet total sudah tidak begitu dipengaruhi oleh anomali lokal, hal ini terlihat pada sedikitnya jumlah dipole magnetik pada peta kontur. Pada Anomali magnetik total di gambarkan pada peta kontur anomali magnetik pada (gambar 2) yaitu berupa dipole sehingga mengandung pasangan klosur positif dan negatif cukup banyak karena sumber anomali magnetik berbaur antara sumber anomali dangkal dan dalam maka dapat ditafsirkan bahwa pada daerah tersebut terdapat benda anomali.

Berdasarkan peta kontur pada gambar 2 dapat dilihat bahwa pola anomali yang berada pada lokasi penelitian terbagi menjadi 3 pola yaitu pola anomali rendah dengan rentang nilai kurang dari $0 \mathrm{nT}$, pola anomali sedang berkisar antara 0 nT sampai dengan $100 \mathrm{nT}$ dan pola anomali tinggi dengan rentang nilai lebih dari $100 \mathrm{nT}$. Pola anomali rendah tersebar ke arah timur laut 
hingga barat laut lokasi penelitian. Pola anomali sedang tersebar memanjang dari arah utara hingga barat laut. Sedangkan pola anomali tinggi tersebar dari arah utara hingga timur lokasi penelitian. Oleh karena itu, lokasi ini ditafsirkan sebagai daerah yang didominasi oleh dan batuan beku yang telah mengalami proses mineralisasi sehingga mengandung oksida besi dan pasir besi.

Setelah harga anomali total didapatkan, selanjutnya melakukan continuasi (pengangkatan). Pada penelitian ini digunakan upward continuation atau pengangkatan ke atas sejauh 100 meter untuk memisahkan antara anomali lokal dan anomali regional sehingga dapat dipisahkan antara batuan penyebab anomali pada posisi yang lebih dalam dengan yang lebih dangkal pada suatu kedalaman tertentu di bawah permukaan daerah pengukuran (gambar 3). Setelah di upward setinggi 100 meter, nilai anomalinya berkurang cukup jauh karena anomali magnetiknya telah di dominankan dikisaran -3000 nT sampai $4000 \mathrm{nT}$ yang sebelumnya berada pada kisaran - $800 \mathrm{nT}$ sampai $1600 \mathrm{nT}$.

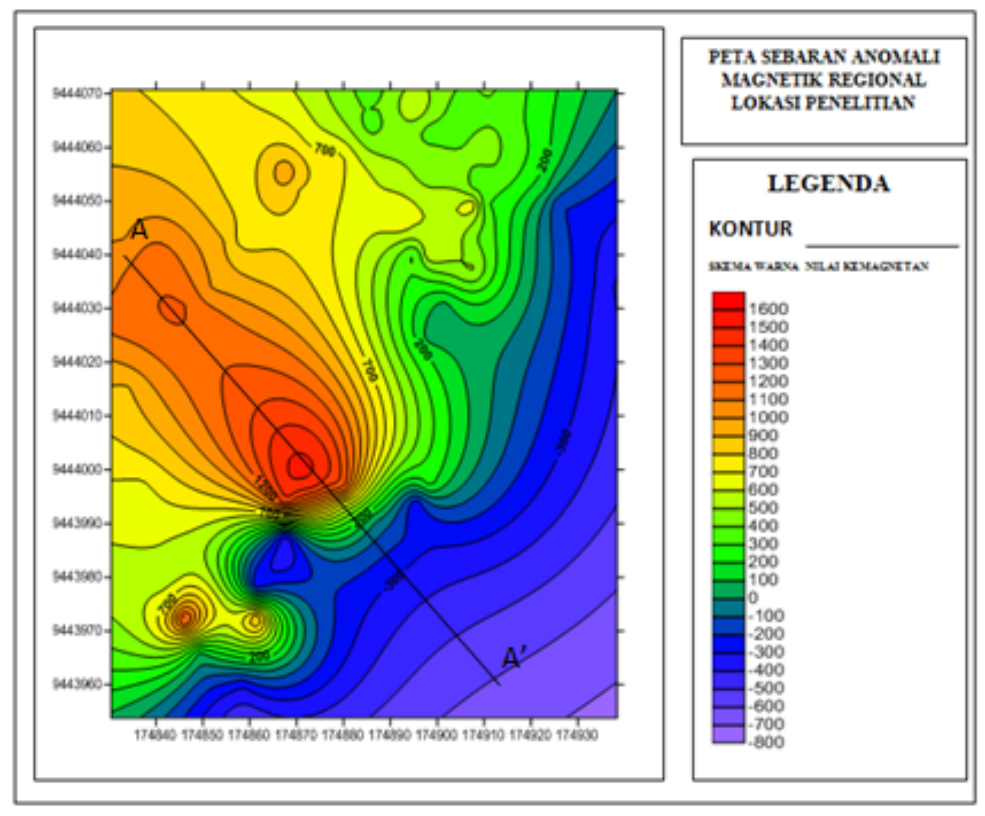

Gambar 4. Bentang Sayatan pada Bidang Anomali Magnetik Lokasi Penelitian

Hal ini menunjukkan bahwa daerah penelitian dengan garis kontur rapat terdapat lembah yang cukup curam sedangkan yang jarang terdapat lembah yang dangkal. Selanjutnya penentuan arah sayatan kontur anomali kemagnetan dengan cara mengoverly peta topografi lokasi penelitian dengan anomali kemagnetan. Seluruh sayatan yang dilakukan pada medan anomali magnetik barat ke timur. Bentangan sayatan berdasarkan kondisi topografi daerah penelitin berupa bidang datar dan miring, langkah ini dilakukan untuk mendugaan lokasi pengambilan data sebaran mineral bawah permukaan (gambar 4).

Interpretasi struktur bawah permukaan daerah anomali magnetik dilakukan dengan menggunakan software geomagnet Mag2DC. Adapun parameter-parameter yang digunakan untuk menampilkan kurva interpretasi ialah nilai IGRF sebesar $42918.2 \mathrm{nT}$, sudut inklinasi sebesar $-26.1239^{\circ}$ dan sudut deklinasi sebesar $0.9113^{\circ}$ daerah penelitian. Nilai suseptibilitas magnetik batuan dan mineral yang diperoleh dari 
interpretasi menjadi acuan penentuan litologi material di lokasi penelitian. Pada gambar 5 model penampang pada lintasan A ke A' menunjukkan dilokasi tersebut terdapat pyrit
(0.05-5 nT), basalt (0.2 nT-175 nT), dan Av batuan metamorf (0-70 nT), Av batuan sedimen (0-18 nT). Pemodelan dilakukan berdasarkan nilai anomali magnetik lintasan pada tabel 1 .

Tabel 1. Nilai Suseptibilitas Material Bawah Permukaan Lintasan A ke A'

\begin{tabular}{ccccc}
\hline No & Suseptibilitas & SI & 3-(SI) & Material Dugaan \\
\hline 1 & 0.5031 & 503.1 & 503.1 & Pyrit \\
2 & 0.1724 & 172.4 & 172.4 & Basalt \\
3 & 0.4253 & 425.3 & 425.3 & Pyrit \\
4 & 0.6594 & 659.4 & 659.4 & Pyrit \\
5 & -0.174 & -174 & 177 & Basalt \\
6 & -0.704 & -704 & 707 & Basalt \\
7 & 0.4036 & 403.6 & 403.6 & Pyrit \\
8 & 0.8996 & 899.6 & 899.6 & Pyrit \\
9 & 0.3009 & 300.9 & 300.9 & pyrit \\
10 & 0.0415 & 41.5 & 41.5 & AV Batuan Metamorf \\
11 & 0.0185 & 18.5 & 18.5 & AV Batuan Sedimen \\
12 & -0.037 & -37 & 40 & AV Batuan Metamorf \\
\hline
\end{tabular}

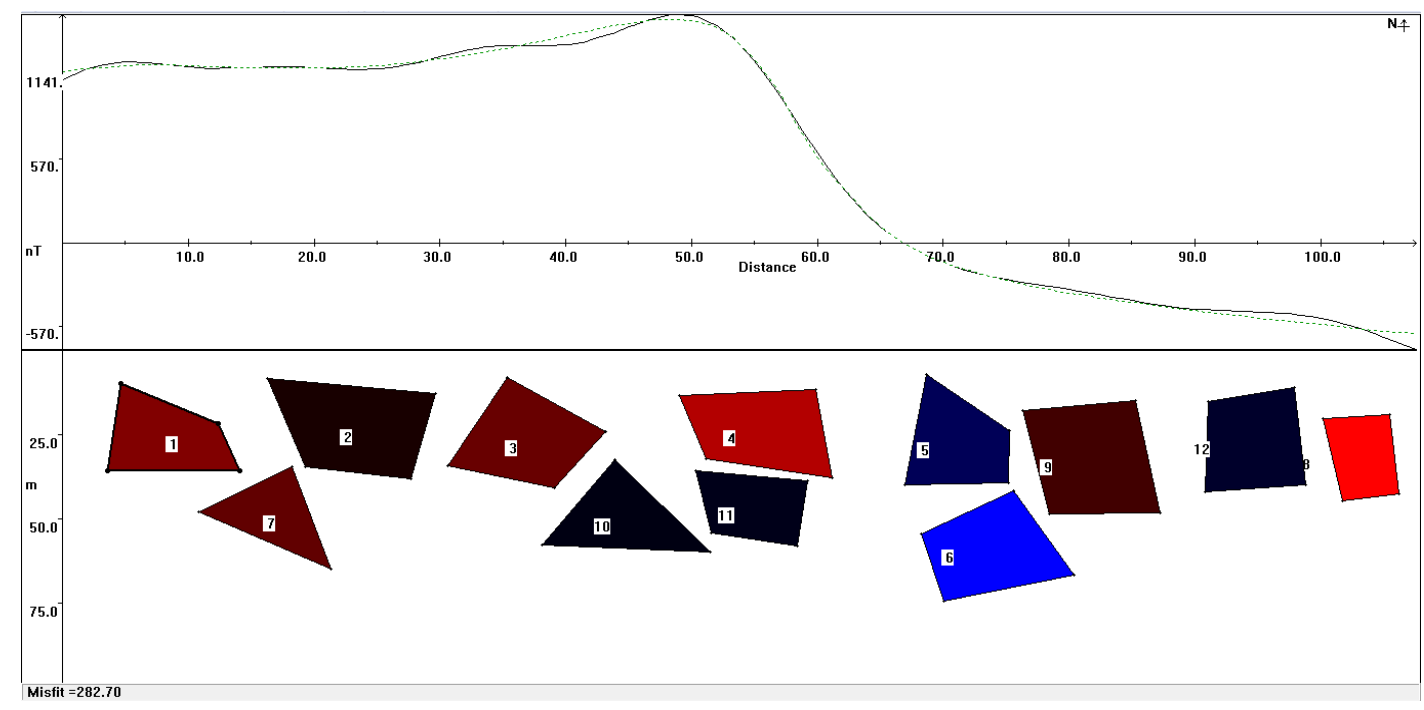

Gambar 5. Pemodelan Material Bawah Permukaan Sayatan A ke A’

Berdasarkan peta geologi Kecamatan plagioklas, biotit, dan mika mineral Bontocani Kabupaten Bone terdapat formasi batuan anggota gunungapi camba yaitu breaksi, lava, dan konglomerat. Pada breaksi dan konglomerat pragman adesit dan basalt, batuan beku adesit yang kaya mineral pirit. Kemudian pada Garanodiorit terjadi dari proses pembentukan magma bersifat asam, terbentuk jauh di dalam kulit bumi sehingga disebut sebagai batuan dalam. Granit mempunyai komposisi utama kuarsa, potash feldspar, penyertaannya antara lain magnetit, ilmenit, pirit (Sukandarrumidi, 2009; Utoyo, 2008).

\section{SIMPULAN}

Kesimpulan dari penelitian ini adalah sebagai berikut:

1. Sebaran anomali magnetik di Kecamatan Bontocani Kabupaten Bone berkisar -800 nT s.d $1600 \mathrm{nT}$ yang menunjukkan ada 3 pola penyebaran anomali magnetik yaitu, pola 
2. anomali rendah (-800-0 nT), pola anomali sedang (0-500 nT), dan pola anomali tinggi (500-1600 nT).

3. Material bawah permukaan di Kecamatan Bontocani Kabupaten Bone adalah basalt, Av batuan metamorf, Av batuan sedimen, dan yang dominan yaitu pirit tersebar yang berasosiasi dengan breksi.

\section{DAFTAR RUJUKAN}

Hidayah, Nur. 2017, Mei Tanggal 4 Mei 2017, Personal interview.

Kahfi, R.A., Yulianto, T. (2008). Identifikasi Struktur Lapisan Bawah Permukaan Daerah Manifestasi Emas dengan Menggunakan Metode Magnetik di Papandaya Garut Jawa Barat. Berkalah Fisika. Vol 11, No 4, Oktober 2008.

Rusli, M.2009. Penelitian Potensi Bahan Magnet Alam di Desa Uekuli Kecamatan Tojo Kabupaten Tojounauna, Provinsi Sulawesi Tenggara. Jurnal Sains Materi Indonesia Desember: 14-19.
Rusita Sitti, Simon Sadok Siregar, Ibrahim Sota. (2016). Identifikasi Sebaran Bijih Besi Dengan Metode Geomagnet di Daerah Pemalongan, Bajuin Tanah Laut, Jurnal Sains FLUX. Vol.13.1

Sukandarrumidi. 2009. Geologi Sejarah. Yogyakarta: Gadjah Mada University Press.

Santosa, B. J. 2013. Magnetic Method Interpretation to Determine Subsurface Structure Around Kelud Volcano. Indian Journal of Applied Research 3(5): 328-331.

Telford, L. G. (1990). Applied Geophysics. New York: Cambridge.

Telford, W.M., Geldart, L.P., and Sheriff, R.F. (2004). Applied Geophysics Second Edition. Edinburgh: Cambridge University Press.

Utoyo, H. 2008. Bijih Besi di Daerah Bontocani Kabupaten Bone Sulawesi Selatan. JSDG. Vol.18. No.1. Oktober 2008.

Zulfitra, M, Latu, Syamsuddin. (2018). Identifikasi Sebaran Mineral Sulfida (Pirit) Menggunakan Metode Geomagnet di Daerah Libureng Kabupaten Bone. Jurnal Geocelebes. Vol. 2. No 1. April 2018, 36-41. 